\title{
European consumers' interest in nutrition information on (sugar-free) chewing gum
}

\author{
Sophie Hieke ${ }^{\mathrm{a}, *}$, Zuzanna Pieniak ${ }^{\mathrm{a}}$, Wim Verbeke ${ }^{\mathrm{b}}$

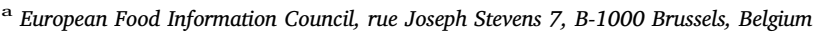 \\ b Ghent University, Department of Agricultural Economics, Coupure links 653, B-9000 Gent, Belgium
}

\section{A R T I C L E I N F O}

\section{Keywords:}

Chewing gum

Consumer

Information

Interest

Label

Nutrition

\begin{abstract}
A B S T R A C T
Much consumer and public health research into nutrition labelling has explored the effects of information provision on consumer behaviour and how it can help consumers in making informed food choices. Among other things, it has been shown that European consumers' interest in and use of nutrition information varies greatly across country and product category. Chewing gum represents an understudied product category where little is known about whether consumers are interested in and would use nutrition information, let alone where they might want to access it due to small pack sizes limiting the space available to provide the information. The present study investigates European consumers $(n=3500)$ in seven countries and shows that while overall interest in nutrition information on chewing gum is relatively low, considerable differences can be observed with regards to users of regular versus sugar-free chewing gum, as well as with regards to low/medium versus heavy users. Sugar-free chewing gum users are more interested in general as well as specific nutrition information that is relevant for chewing gum, compared to regular chewing gum users. And low and medium user groups have a better awareness of which nutrients are relevant for chewing gum, compared to heavy users who appear less concerned about nutrition and health. The results provide insights into European consumers' attitudes towards nutrition information for chewing gum, and alternative sources of such information provision as pack size is a limiting factor in regards to this product.
\end{abstract}

\section{Introduction}

\subsection{Motivation for the study}

One of the pillars of the European Food Information to Consumers Regulation (EU 1169/2011) is the provision of relevant product information to achieve "a high level of health protection for consumers and to guarantee their right to information (...)". The supra-national legislation regulates how, where and under what circumstances nutrition information is to be presented on-pack, following the general principle of the food law that is to provide a basis for consumers to make informed (food) choices.

Both as a response to and a driver of these regulatory developments, research into nutrition labelling has explored the effects of information provision on consumer behaviour and how it can help consumers in making informed food choices (Campos, Doxey, \& Hammond, 2011; Grunert, Fernandez-Celemin, Wills, Storcksdieck genannt Bonsmann, \& Nureeva, 2010; Grunert, Wills, \& Fernandez-Celemin, 2010; Hersey, Wohlgenant, Arsenault, Kosa, \& Muth, 2013;
Hieke \& Wills, 2012). Some of the major research questions include "what type of nutrition information are consumers interested in?" and "where and how should nutrition information be provided to consumers to be effective?".

European consumers' interest in nutrition information has been shown to vary across regions, age and gender with women, parents of children living at home, older consumers and consumers in Northern and Central Europe relative to Southern Europe displaying a tendency to be more interested in nutrition information (EC Directorate General for Health \& Consumer Protection, 2005; European Heart Network, 2007; Gregori et al., 2014; Grunert, Fernandez-Celemin et al., 2010). These variations are due to differences in the history of health policies and nutrition-related initiatives but also due to cultural differences (Grunert et al., 2012).

One of the most prominent frameworks in food label use has shown that for consumers to respond to nutrition information, they need first and foremost to be exposed to the nutrition information. Exposure only translates potentially into behaviour when the information is being perceived. Through understanding and liking, perception can

\footnotetext{
* Corresponding author.

E-mail addresses: sophie.hieke@eufic.org (S. Hieke), zuzanna.pieniak@eufic.org (Z. Pieniak), wim.verbeke@ugent.be (W. Verbeke).
} 
ultimately lead to use, but the whole process is influenced by a number of factors, including interest in and knowledge about nutrition issues (Grunert \& Wills, 2007).

The exact role of nutrition knowledge in label use, however, is yet to be understood. While some research has shown that it may facilitate label use by increasing its perceived benefits and by increasing its efficiency (Drichoutis, Lazaridis, \& Nayga, 2006), other studies reported that nutrition knowledge has no significant effect on consumers' use of nutrition information on food labels, but is rather explained by a person's interest in healthy eating (Grunert, Wills et al., 2010) and personal motivation rather than knowledge-based personal ability to process such information (Hung, Grunert, Hoefkens, Hieke, \& Verbeke, 2017).

Research has shown that consumers perceive nutrients as either qualifying (i.e., vitamins) or disqualifying (i.e., fat, sugars). For example, nutrients for which a strong interest has been reported are fat, energy, salt, and sugar, which are all so-called disqualifying nutrients (Grunert \& Wills, 2007). Other studies reported that consumers consider the nutritional value of foods as important when selecting foods, particularly when it comes to qualifying nutrients (Hoefkens, Verbeke, \& Van Camp, 2011). This type of nutrition information is likely to determine consumers' level of interest in various food products and appears to have a strong impact on food choice.

Interest in and use of nutrition information has also been shown to vary across food product categories (Grunert, Fernandez-Celemin et al., 2010). One reason for this could be that, in the minds of consumers, not all foods are perceived as equally important with respect to health, i.e. to have an (equal) potential impact on one's health. This likely affects whether or where consumers search for nutrition information for different products. In addition, the provision of nutrition information through packaging is not evident for all types of foods, owing to different reasons, the most obvious one being the lack of packaging (e.g., in case of unpacked products), or products with little or relatively small packaging. A growing body of literature focusses on alternative ways to present nutrition information, from in-store/on-shelf information provisions (Freedman \& Connors, 2010; Seymour, Yaroch, Serdula, Blanck, \& Khan, 2004) to online provisions, e.g. via retail websites (Epstein et al., 2016; Stones, 2106) and app-based nutrition information provision (Dimitriou et al., 2017). There is, however, little research available on where consumers might like to find and access nutrition information if not available on-pack.

\subsection{Scope on chewing gum}

A very specific type of food product is chewing gum for which there is evidence that it may not be considered by consumers as a 'food' as such as it is not ingested (Gregori et al., 2014), and therefore perceived as less important in terms of contributing to one's health. Furthermore, chewing gum packaging does not leave much room to provide detailed nutrition information on-pack. A European food label audit showed that product categories such as chewing gum, spices, tea and coffee rarely carried the tabular nutrition labelling (Storcksdieck genannt Bonsmann et al., 2010), due to limiting factors such as pack size as well as the requirement to display information in several languages on-pack. Under the new European Regulation (EU 1169/2011), nutrition information is now mandatory on every pre-packaged food that makes a nutrition or health claim. Sugar-free chewing gum hence is required to provide nutrition information because of the claim made on-pack. Alternatively, manufacturers can decide not to label the chewing gum as "sugar-free" which in turn would eliminate relevant information to consumers who prefer and/or predominantly purchase sugar-free chewing gum.

Recent research shows that a vast majority of European consumers use chewing gum regardless of their nationality, age or gender. Intakes are similar across country with an average of $1.87 \mathrm{~g}$ per day. This corresponds to about 0.75 pieces per day in children and 0.98 pieces per day in adolescents and adults, respectively (Hearty, Lau, \& Roberts,
2014). The use of chewing gum has long been advocated as a result of research into health aspects such as the prevention of dental caries (Deshpande \& Jadad, 2008; Ribelles Llop, Guinot Jimeno, Mayné Acién, \& Bellet Dalmau, 2010), appetite regulation (Hetherington \& Boyland, 2007; Hetherington \& Regan, 2011) and positive effects on stress and performance (Onyper, Carr, Farrar, \& Floyd, 2011; Smith, Chaplin, \& Wadsworth, 2012). Particularly the use of polyol-containing chewing gum has been shown to be beneficial for dental health. Chewing sugar-free gum increases the production of saliva, which can help neutralize plaque acid, wash away food debris and demineralise tooth enamel to help strengthen teeth. Research evidence supports using polyol-containing chewing gum as part of normal oral hygiene to prevent dental caries (Deshpande \& Jadad, 2008; Ribelles Llop et al., 2010). Additionally, chewing gum for about $45 \mathrm{~min}$ can suppress hunger and cravings for snacks and can promote the feeling of fullness (Ribelles Llop et al., 2010) which may make it a useful adjunct to weight management for some individuals (Hetherington \& Regan, 2011). Lastly, chewing gum has been found to reduce stress (both at work and outside work), fatigue, anxiety and depression (Smith et al., 2012) and lead to a more positive mood (Hetherington \& Regan, 2011; Smith et al., 2012).

To date, little is known about consumer attitudes towards chewing gum, with the exception of a study on packaging design aspects and their influence on people's willingness-to-buy (Rebollar, Lidón, Serrano, Martín, \& Fernández, 2012), a comparison of methods to test flavour and texture attributes of chewing gum (Galmarini, Symoneaux, Visalli, Zamora, \& Schlich, 2016) and consumer product liking/rating after one time only vs. repeat exposure (Galmarini, Symoneaux, Visalli, Zamora, \& Schlich, 2015).

As part of the research into functional foods, consumer attitudes towards chewing gum (versions containing xylitol, more precisely) have been studied somewhat more frequently during the past decades. Urala and Lähteenmäki (2004) found that Finnish consumers who obtained reward from using functional foods were most willing to use all functional food examples given in the study, except for chewing gum and sweets with xylitol. Consumers who saw functional foods as part of a healthy diet and did not perceive risks connected to functional foods were in fact less willing to use sweets and chewing gum with xylitol (Urala \& Lähteenmäki, 2004). A follow-up study in 2007 by the same authors revealed that the willingness of Finnish consumers to use chewing gum and sweets with xylitol had slightly decreased whereas the perceived reward from eating (other) functional foods increased strongly and on a statistically significant level. Consumers were even more willing to use the functional food examples listed in the survey, except chewing gum and sweets with xylitol (Urala \& Lätheenmäki, 2007). These findings are in line with an Australian study by Williams and colleagues who reported that health claims on tea, yoghurt, soup and brown bread received significantly higher ratings on intention to try than similar claims made on chewing gum, ice cream, margarine and meat replacers (Williams, Ridges, Batterham, Ripper, \& Hung, 2008). While these studies thus suggest that chewing gum is perceived by consumers as a less suitable carrier for functional ingredients and related claims, they reveal little about consumers' actual interest in the product category as such, and in nutrition information on this product in specific. Aside from these studies and despite the potential health benefits of chewing gum, to date there is little data available on European consumers' interest in and knowledge about nutrition information related to chewing gum. This includes the type of nutrients that consumers are most interested in.

\subsection{Study objectives}

Combining the above with a historically low prevalence of nutrition information and labelling on chewing gum packaging (i.e. low exposure), several determinants of the [nutrition label effectiveness] framework by Grunert and Wills (2007) are unknown. To date, it is not 
clear whether consumers are interested in nutrition information on (sugar-free) chewing gum and how relevant this type of information is to them. If so, considering pack size limitations when providing nutrition information, it remains a question where consumers would like to find this information if not on-pack. Effectively aiding them in making informed choices is thus hampered given the current knowledge status. As such, it is of interest to profile European consumers based on their interest in various nutrients, in order to understand information search behaviour and ultimately better tailor the nutrition information provision on a product like chewing gum, in this specific case.

The objective of this paper is to investigate European consumers' interest in nutrition information on (sugar-free) chewing gum and their preferred way of information provision. Seven countries have been selected for data collection, covering the geographical North-South and East-West axes of Europe: United Kingdom, France, Germany, Italy, Sweden, Poland, and Estonia. Three specific research questions are addressed in the present study:

1) To what extent are consumers interested in nutrition information on (sugar-free) chewing gum? To what extent do consumers read nutrition labels on chewing gum? If so, what nutrition information are they looking for?;

2) What factors explain differences in the interest in nutrition information on chewing gum between consumer groups?; and

3) Where would consumers like to find this information, if not available on-pack?

\section{Materials and methods}

\subsection{Research approach and sampling}

Cross-European data were collected during January 2014 through a cross-sectional quantitative online survey with samples close to national representativeness for age, gender and region in seven European countries: United Kingdom, France, Germany, Italy, Sweden, Poland and Estonia. The choice of countries to undertake this study in was motivated by several factors, including a representation of the core markets for chewing gum in the European Union (United Kingdom, France, Germany and Italy) (Hearty et al., 2014) as well as representatives from Central Europe (Poland), the Baltics (Estonia) and Scandinavia (Sweden), in order to cover the main geographic areas in Europe, from North to South and East to West. Non-probability quota sampling with chewing gum use (regular versus sugar-free) as quota control variables was used. A total of 3500 chewing gum users, i.e. 500 participants per country, between the ages of 18 and 65 years were recruited from the online access proprietary panel of a contracted professional market research agency. All procedures for contact and questionnaire administration were electronic via the market research agency. Detailed socio-demographic characteristics of the national and pooled samples are provided in Table 1.

\subsection{Questionnaire content and pre-testing}

The questionnaire consisted of six sections dealing with (1) general health and nutrition interest, (2) nutrition knowledge, (3) chewing gum behaviour, (4) interest in nutrition information on chewing gum and use of chewing gum nutrition labels, (5) (nutrition) information search behaviour, and (6) socio-demographics. The master questionnaire was developed in English and translated into the national languages using back-translation to ensure linguistic equivalence across the study countries (Brislin, 1970; Maneesriwongul \& Dixon, 2004). The questionnaire was extensively pre-tested through personal interviews with 15-20 participants in each country. Fieldwork started after editing, correcting, electronic programming and additional pre-testing of the electronic versions of the questionnaire.

\subsection{Measurement and scaling}

General health interest was measured on a 7-point Likert scale by means of 12 items (e.g., "I always follow a healthy and balanced diet", "It is important for me that my diet is low in fat", "The healthiness of food has little impact on my food choices") based on Roininen, Lähteenmäki, and Tuorila (1999) (Cronbach's alpha =0.85). Additionally, general interest in reading about nutrition was measured on a 5-point interval scale ranging from "Not at all interested" $(=1)$ to "Extremely interested" (=5).

Subjective or perceived knowledge of participants was measured on a 7-point Likert scale by means of four items following Pieniak, Aertsens, and Verbeke (2010) (e.g., "My friends consider me as an expert in healthy foods", "I have a lot of knowledge about how to prepare a healthy meal", "I know which food is healthy for me") (Cronbach's alpha $=0.87$ )

Objective nutrition knowledge was measured by three components. The first component was based on the scale developed by DicksonSpillmann, Siegrist, and Keller (2011), covering the knowledge on expert recommendations about healthy eating in general. The original scale consists of 20 multiple-choice questions which was extended with four questions specifically related to chewing gum (i.e. "Sugar-free chewing gum does not contain any calories", "The same amount of sugar-free and regular chewing gum contains the same amount of calories", "One gram of sugar contains the same amount of calories as one gram of sweetener", "Sugar-free chewing gum helps neutralise plaque acids"). The second component consisted of two items measuring participants' knowledge on adult's daily energy requirements. The third component measured participants' knowledge on the calorie content of food and drink products based on Grunert, Fernandez-Celemin et al. (2010). For indicated serving sizes of seven different products (including one piece of regular and sugar-free chewing gum), participants were asked to choose the amount of calories in that serving from a scale consisting of twelve (or seven for chewing gum) calorie ranges. The answer for each item was coded as right or wrong. For analysis, an overall index of objective nutrition knowledge, ranging from 0 to 3 , was calculated as follows:

\section{Objective nutrition knowledge}

$$
\begin{aligned}
= & \text { (number of correct answers on expert recommendations about } \\
& \text { healthy eating/24) } \\
& +(\text { number of correct answers on energy requirements } / 2) \\
& +(\text { number of correct answers on calorie content of food and drink } \\
& \text { products/7). }
\end{aligned}
$$

Participants' chewing gum behaviour was characterised by the type of chewing gum used (i.e. regular versus sugar-free chewing gum) and the usage frequency (i.e. very frequently, frequently, occasionally). The latter was used to distinguish heavy, medium and low users of chewing gum based on self-reported usage.

Interest in nutrition information on chewing gum was assessed using questions about the type of nutrition information (including energy (calories), carbohydrates, sugars, polyols, fibre, fat, saturated fat/ saturates, protein, salt/sodium) that the participants are looking for when reading labels on a chewing gum package. A 5-point scale was used ranging from "Never" $(=1)$ to "Always" $(=5)$, in addition to a "Don't know" option. Based on this scale, two subscales were defined depending on the relevance of the type of nutrition information to chewing gum as a product category. The interest in nutrition information relevant for chewing gum was obtained after summation across the items energy (calories), carbohydrates, sugars, and polyols (i.e. chewing gum is an important source of those nutrients). The scores on the items fibre, fat, saturated fat/saturates, protein, and salt/sodium were summated to create the scale of interest in nutrition information irrelevant for chewing gum. 
Table 1

Sample characteristics $(\%, \mathrm{n}=3500)$.

\begin{tabular}{|c|c|c|c|c|c|c|c|c|c|}
\hline & & \multirow[b]{2}{*}{$\begin{array}{l}\text { Pooled sample } \\
\mathrm{N}=3500\end{array}$} & \multicolumn{7}{|c|}{ Country (\%) } \\
\hline & & & $\begin{array}{l}\mathrm{UK} \\
\mathrm{n}=500\end{array}$ & $\begin{array}{l}\text { France } \\
\mathrm{n}=500\end{array}$ & $\begin{array}{l}\text { Germany } \\
\mathrm{n}=500\end{array}$ & $\begin{array}{l}\text { Italy } \\
\mathrm{n}=500\end{array}$ & $\begin{array}{l}\text { Sweden } \\
\mathrm{n}=500\end{array}$ & $\begin{array}{l}\text { Poland } \\
\mathrm{n}=500\end{array}$ & $\begin{array}{l}\text { Estonia } \\
\mathrm{n}=500\end{array}$ \\
\hline \multirow[t]{2}{*}{ Gender } & Male & 47.9 & 48.2 & 48.6 & 48.6 & 48.4 & 48.2 & 48.0 & 45.6 \\
\hline & Female & 52.1 & 51.8 & 51.4 & 51.4 & 51.6 & 51.8 & 52.0 & 54.4 \\
\hline \multirow[t]{3}{*}{ Age } & $18-34 y$ & 49.7 & 49.6 & 49.8 & 50.0 & 50.0 & 48.2 & 50.4 & 49.6 \\
\hline & $35-44 y$ & 25.2 & 25.2 & 25.2 & 25.0 & 25.0 & 25.8 & 24.6 & 25.4 \\
\hline & $45-64 y$ & 25.2 & 25.2 & 25.0 & 25.0 & 25.0 & 26.0 & 25.0 & 25.0 \\
\hline \multirow[t]{3}{*}{ Education } & Low & 54.4 & 58.9 & 45.0 & 69.1 & 47.2 & 62.5 & 44.2 & 54.3 \\
\hline & Medium & 37.5 & 29.8 & 43.4 & 30.1 & 47.2 & 30.6 & 46.6 & 35.0 \\
\hline & High & 8.1 & 11.3 & 11.7 & 0.8 & 5.7 & 6.9 & 9.3 & 10.8 \\
\hline \multirow[t]{2}{*}{ Children in household ( $\leq 15 \mathrm{y})$} & Yes & 38.0 & 43.9 & 45.3 & 30.6 & 35.0 & 28.9 & 41.0 & 41.3 \\
\hline & No & 62.0 & 56.1 & 54.7 & 69.4 & 65.0 & 71.1 & 59.0 & 58.7 \\
\hline \multirow[t]{3}{*}{ User group } & Low & 23.4 & 26.3 & 31.6 & 22.4 & 21.2 & 17.9 & 29.3 & 15.2 \\
\hline & Medium & 40.2 & 45.1 & 39.4 & 41.6 & 45.5 & 32.7 & 46.0 & 31.1 \\
\hline & Heavy & 36.4 & 28.7 & 29.0 & 36.0 & 33.3 & 49.4 & 24.7 & 55.7 \\
\hline \multirow[t]{2}{*}{ Gum type } & Sugar free & 71.8 & 74.8 & 71.4 & 67.8 & 70.2 & 75.4 & 75.0 & 68.2 \\
\hline & Regular & 28.2 & 25.2 & 28.6 & 32.2 & 29.8 & 24.6 & 25.0 & 31.8 \\
\hline
\end{tabular}

A median split was used to form high and low subgroups regarding interest in [relevant, irrelevant] nutrition information on chewing gum. As such, four subgroups of individuals were obtained: those with (1) low interest in both relevant and irrelevant nutrition information ( $\mathrm{n}=1640$ ), (2) low interest in relevant and high interest in irrelevant nutrition information $(\mathrm{n}=80)$, (3) high interest in relevant and low interest in irrelevant nutrition information $(n=587)$, and (4) high interest in both relevant and irrelevant nutrition information on chewing gum ( $\mathrm{n}=1193)$.

Additionally, participants' top-three reasons for not reading nutrition information on chewing gum packages were assessed among a list of 13 statements (e.g., "I haven't considered it so far", "I don't think there is a nutritional value in chewing gum", "I can't read the information, it's too small").

Participants were also asked where they would prefer to find nutrition information for chewing gum if it was not possible to display that information on pack. Presented alternative information sources included advertising in magazines, product/brand website, smartphone apps, in the shop aisle/on-shelf among others. Participants indicated their degree of preference for each information source on a 5-point interval scale ranging from "Not preferred at all" $(=1)$ to "Very much preferred" (=5).

Socio-demographic characteristics included the country of origin (United Kingdom, France, Germany, Italy, Sweden, Poland and Estonia), gender, age, educational level (low = primary and lower secondary education completed; medium $=$ higher secondary education completed; high = university-level diploma and higher completed), and the presence of children aged 15 years or less in the household.

\subsection{Statistical analyses}

Questionnaires were edited and quality-checked by the market research agency in order to ensure accuracy and precision of the response prior to coding and transcription of the data into SPSS 21.0 format (IBM SPSS, Armonk, NY, USA). Given the large sample sizes and very low numbers of missing responses, pairwise deletion was used as the method for treating missing values.

Statistical analyses were carried out with SPSS Statistics 21.0 and Stata 13.0 (Statacorp, College Station, TX, USA). Cronbach's alpha coefficients were computed to measure the internal consistency of the scales. Data processing and analysis included descriptive analysis (frequency distributions, means and standard deviations (S.D.)), bivariate (chi-square tests for association between categorical variables, independent samples or paired samples t-tests for comparison of means, one-way ANOVA or the corresponding non-parametric tests for comparison of means between groups) and multivariate analysis (multinomial logistic regression). A p-value of 0.05 has been used as the threshold for statistical significance.

Multinomial logistic regression analysis was used to estimate the association between consumers' interest in nutrition information on chewing gum and their preference for alternative means of providing nutrition information on chewing gum while controlling for chewing gum behaviour (interaction between type of chewing gum used and the usage frequency). Results are reported as odds ratios (OR) with 95\% confidence intervals (95\% CI). The likelihood ratio chi-square statistic and McFadden's Pseudo- $\mathrm{R}^{2}$ are reported as indicators of the model fit (McFadden, 1974).

\section{Results}

\subsection{Interest in nutrition information on (sugar-free) chewing gum} (descriptive findings)

In general, participants were interested in nutrition information (Table 2). In spite of their relatively high interest in general nutrition

Table 2

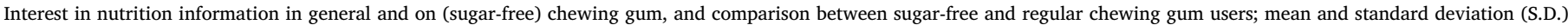

\begin{tabular}{|c|c|c|c|c|}
\hline & Total sample $(\mathrm{n}=3500)$ & Sugar-free chewing gum users $(n=2513)$ & Regular chewing gum users $(\mathrm{n}=987)$ & p-value ${ }^{\S}$ \\
\hline General interest in nutrition information ${ }^{*}$ & $3.49(0.92)$ & $3.57(0.91)$ & $3.27(0.91)$ & $<0.001$ \\
\hline Interest in nutrition information on chewing gum" & $1.88(1.02)$ & $1.97(1.05)$ & $1.65(0.92)$ & $<0.001$ \\
\hline Interest in information relevant for chewing gum ${ }^{\#}$ & $2.16(1.14)$ & $2.29(1.16)$ & $1.82(1.01)$ & $<0.001$ \\
\hline Interest in information irrelevant for chewing gum ${ }^{\#}$ & $1.62(1.01)$ & $1.67(1.04)$ & $1.49(0.89)$ & $<0.001$ \\
\hline
\end{tabular}

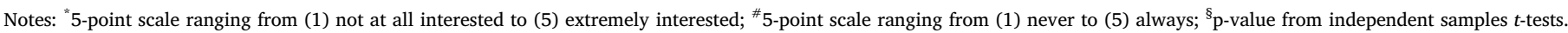


Table 3

Nutrients most and least looked for when reading labels on chewing gum; mean and standard deviation (S.D.) ${ }^{*}$

\begin{tabular}{|c|c|c|c|c|}
\hline & \multicolumn{2}{|c|}{$\begin{array}{l}\text { Nutrients most looked for when reading } \\
\text { labels on chewing gum }\end{array}$} & \multicolumn{2}{|c|}{$\begin{array}{l}\text { Nutrients least looked for when reading } \\
\text { labels on chewing gum }\end{array}$} \\
\hline 1 & Sugars & $2.82(1.63)$ & Polyols & $1.45(0.95)$ \\
\hline \multirow[t]{2}{*}{2} & Energy (calories) & $2.30(1.47)$ & Fibre & $1.56(1.05)^{\#}$ \\
\hline & & & Salt/sodium & $1.58(1.06)^{\#}$ \\
\hline \multirow[t]{2}{*}{3} & Carbohydrates & $1.88(1.31)$ & Protein & $1.59(1.08)^{\#}$ \\
\hline & & & Saturated fat & $1.59(1.07)^{\#}$ \\
\hline
\end{tabular}

Notes: * Measured on 5-point scale ranging from (1) never to (5) always. \# The mean scores for fibre versus salt/sodium and for protein versus saturated fat are not significantly different following paired samples $t$-tests with p-values of 0.088 and 0.734 , respectively.

information, respondents reported relatively low interest in nutrition information placed on chewing gum. Users of sugar-free chewing gum were significantly more interested in general nutrition information compared with regular chewing gum users.

Concerning the type of nutrition information participants were interested in when reading labels on a chewing gum package, information relevant for chewing gum (i.e. energy (calories), carbohydrates, sugars, polyols) received a higher frequency compared to information irrelevant for this product (because chewing does not contain these nutrients to any significant extent; i.e. fibre, fat, saturated fat/saturates, protein, salt/sodium). Users of sugar-free chewing gum were significantly more interested in specific nutrition information (both relevant and irrelevant) on chewing gum than regular chewing gum users.

The top three nutrients that participants were most interested in when reading labels on a chewing gum package were sugars, energy (calories) and carbohydrates (Table 3). No differences in ranking existed between the sugar-free gum users and regular chewing gum users. By contrast, the top nutrients that participants were least interested in when reading labels on chewing gum were polyols, fibre and salt/sodium as well as protein and saturated fat. In this case, small differences in the ranking between sugar-free and regular chewing gum users existed, but the five nutrients with the least interest were the same for both groups.

The top three reasons for not reading nutrition information on chewing gum packages $(n=899)$ were: (1) I haven't considered it so far (indicated by $46 \%$ of respondents, among two other reasons); (2) I don't think there is any nutritional value in chewing gum (28\%) and (3) I don't use chewing gum very often (24\%).

\subsection{Interest in nutrition information, chewing gum use and socio- demographics}

Significant differences existed between the level of interest in nutrition information on chewing gum and chewing gum use (Table 4). Consumers with a low interest in nutrition information relevant for chewing gum (regardless of their interest in irrelevant information) were more likely to be heavy users of chewing gum. Consumers with a high interest in nutrition information relevant for chewing gum (regardless of their interest in irrelevant information) were more likely to be medium users of chewing gum and more likely to be users of sugarfree chewing gum.

Comparison of the respondents with different levels of interest in nutrition information on chewing gum across the countries, age and gender categories revealed significant differences. Consumers with a high interest in nutrition information relevant for chewing gum and a low interest in irrelevant information were more likely to be female and older. Additionally, there were relatively more men with a high interest in all kinds of nutrition information on chewing gum as compared to the distribution in the total sample.

With regard to the cross-country differences, relatively more
Estonian and Swedish respondents reported a low interest in both relevant and irrelevant nutrition information. Relatively more British and Polish respondents displayed a low interest in relevant and high interest in irrelevant nutrition information, whereas more German and French respondents showed a high interest in relevant and low interest in irrelevant nutrition information placed on chewing gum package. Finally, relatively more Italian and Polish respondents reported a high interest in both relevant and irrelevant nutrition information. No relation between the level of interest in nutrition information on chewing gum and both education and the presence of children in the household aged 15 years or under was found.

\subsection{Interest in nutrition information on chewing gum, general health interest and nutrition knowledge}

Comparison of the general health interest and nutrition knowledge between respondents with different levels of interest in nutrition information on chewing gum revealed significant differences with medium effect sizes based on Harlow (2005) (Table 5). Respondents with a high interest in nutrition information relevant for chewing gum and a low interest in irrelevant information had a significantly higher general health interest and objective nutrition knowledge compared to the others. Respondents with a high interest in both relevant and irrelevant nutrition information perceived themselves to be more knowledgeable about nutrition compared to the others. Finally, respondents with a low interest in both relevant and irrelevant nutrition information had a significantly lower general health interest and nutrition knowledge (both objective and subjective).

\subsection{Interest in providing nutrition information on chewing gum by alternative means}

Regardless different consumer segments, respondents were most interested in receiving nutrition information on chewing gum in the shop aisle/on-shelf, followed by information placed on a product/brand website and health and nutrition website (Table 6). Respondents were the least interested in receiving nutrition information about chewing gum on banners, posters, billboards or any other advertisement placed outside, through a smart phone apps or product/brand social network sites. Interest in nutrition information on chewing gum from alternative information sources generally increases from the consumer group with a low interest in relevant and irrelevant information to the consumer group with a high interest in both types of information (Table 6). Effect sizes are medium based on Harlow (2005).

\subsection{Interest in nutrition information on sugar-free vs. regular chewing gum: multinomial logistic regression}

In order to analyse the associations between respondents' interests in nutrition information on chewing gum and their preference for alternative means of providing nutrition information on chewing gum while controlling for chewing gum behaviour, multinomial logistic regressions have been performed. Table 7 presents the odds-ratios of the level of interest in nutrition information on chewing gum, depending on consumers' preferences for alternative means of providing nutrition information on chewing gum and their chewing gum consumption behaviour. The likelihood ratio chi-square of 727.44 with a p-value $<$ 0.001 indicates that the model as a whole fits significantly better than an empty model (i.e., a model with no predictors) (McFadden's Pseudo$\left.\mathrm{R}^{2}=0.103\right)$.

Each unit increment in respondents' preference score for health and nutrition websites, added to the odds of having a low interest in both relevant and irrelevant nutrition information on chewing gum by 0.86 times when the other variables in the model are held constant. In other words, consumers with a higher preference for health and nutrition websites (as an alternative source of nutrition information on chewing 
Table 4

Level of interest in nutrition information on chewing gum by chewing gum behaviour and socio-demographics characteristics, $\%$, $\mathrm{n}=3500$.

\begin{tabular}{|c|c|c|c|c|c|c|}
\hline & & \multicolumn{4}{|c|}{ Level of interest in nutrition information on chewing gum } & \multirow[b]{2}{*}{ p-value ${ }^{\#}$} \\
\hline & & $\begin{array}{l}\text { Low in relevant, low in } \\
\text { irrelevant }(n=1640)\end{array}$ & $\begin{array}{l}\text { Low in relevant, high in } \\
\text { irrelevant }(n=80)\end{array}$ & $\begin{array}{l}\text { High in relevant, low in } \\
\text { irrelevant }(n=587)\end{array}$ & $\begin{array}{l}\text { High in relevant, high in } \\
\text { irrelevant }(n=1193)\end{array}$ & \\
\hline \multirow[t]{3}{*}{ User group } & Low user & 20.4 & 21.3 & 24.7 & 27.0 & $<0.001$ \\
\hline & Medium user & 35.2 & 38.8 & 41.6 & 46.5 & \\
\hline & Heavy user & 44.4 & 40.0 & 33.6 & 26.5 & \\
\hline \multirow[t]{2}{*}{ Gum type } & Sugar free & 63.2 & 71.3 & 85.4 & 77.1 & $<0.001$ \\
\hline & Regular & 36.8 & 28.8 & 14.7 & 22.9 & \\
\hline \multirow[t]{7}{*}{ Country } & UK & 14.0 & 23.8 & 8.4 & 17.0 & $<0.001$ \\
\hline & France & 14.8 & 13.8 & 16.4 & 12.7 & \\
\hline & Germany & 12.7 & 12.5 & 18.2 & 14.7 & \\
\hline & Italy & 9.6 & 8.8 & 16.7 & 20.0 & \\
\hline & Sweden & 16.8 & 10.0 & 16.0 & 10.3 & \\
\hline & Poland & 11.6 & 18.8 & 12.4 & 18.6 & \\
\hline & Estonia & 20.5 & 12.3 & 11.9 & 6.7 & \\
\hline \multirow[t]{2}{*}{ Gender } & Male & 47.8 & 46.2 & 40.5 & 51.9 & $<0.001$ \\
\hline & Female & 52.2 & 53.8 & 59.5 & 48.1 & \\
\hline Age & Median & $34^{\mathrm{a}}$ & $34^{\mathrm{a}}$ & $38^{\mathrm{b}}$ & $34^{\mathrm{a}}$ & $<0.001^{\S}$ \\
\hline \multirow[t]{3}{*}{ Education } & Low & 55.9 & 65.0 & 53.7 & 52.0 & 0.079 \\
\hline & Medium & 36.2 & 23.7 & 38.4 & 39.9 & \\
\hline & High & 7.9 & 11.3 & 7.9 & 8.1 & \\
\hline \multirow{2}{*}{$\begin{array}{l}\text { Children in household } \\
\qquad(\leq 15 y)\end{array}$} & Yes & 36.3 & 41.2 & 36.5 & 40.8 & 0.079 \\
\hline & No & 63.7 & 58.8 & 63.5 & 59.2 & \\
\hline
\end{tabular}

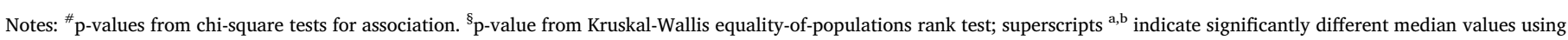
the non-parametric Wilcoxon's rank-sum test (Mann-Whitney $U$ test).

Table 5

Level of interest in nutrition information on chewing gum by general health interest and nutrition knowledge; mean and standard deviation (S.D.).

\begin{tabular}{|c|c|c|c|c|c|c|}
\hline & \multicolumn{4}{|c|}{ Level of interest in nutrition information on chewing gum } & \multirow[b]{2}{*}{ p-value ${ }^{\#}$} & \multirow[b]{2}{*}{$\begin{array}{l}\text { Effect size } \\
\eta^{2}\end{array}$} \\
\hline & $\begin{array}{l}\text { Low in relevant, low in } \\
\text { irrelevant }(n=1640)\end{array}$ & $\begin{array}{l}\text { Low in relevant, high in } \\
\text { irrelevant }(\mathrm{n}=80)\end{array}$ & $\begin{array}{l}\text { High in relevant, low in } \\
\text { irrelevant }(n=587)\end{array}$ & $\begin{array}{l}\text { High in relevant, high in } \\
\text { irrelevant }(\mathrm{n}=1193)\end{array}$ & & \\
\hline General health interest & $4.00(1.06)^{\mathrm{a}}$ & $4.36(0.91)^{\mathrm{b}}$ & $4.64(1.00)^{\mathrm{c}}$ & $4.55(0.96)^{b}$ & $<0.001$ & 0.11 \\
\hline $\begin{array}{l}\text { Subjective nutrition } \\
\text { knowledge }\end{array}$ & $4.24(1.38)^{\mathrm{a}}$ & $4.66(1.29)^{b}$ & $4.90(1.21)^{b}$ & $5.12(1.17)^{\mathrm{c}}$ & $<0.001$ & 0.10 \\
\hline $\begin{array}{l}\text { Objective nutrition } \\
\text { knowledge }\end{array}$ & $0.95(0.42)^{\mathrm{a}}$ & $1.05(0.42)^{\mathrm{a}, \mathrm{b}, \mathrm{c}^{*}}$ & $1.15(0.37)^{\mathrm{c}}$ & $1.06(0.40$ & $<0.001$ & 0.10 \\
\hline
\end{tabular}

Notes: ${ }^{\#}$ p-value from one-way ANOVA F-tests; superscripts ${ }^{a, b, c}$ indicate significantly different means using the Tukey HSD post hoc comparison tests.

gum) are more likely to have a high interest in nutrition information relevant for chewing gum and a low interest in irrelevant information, i.e. they have a higher likelihood of belonging to the reference group in our analysis (compared to having a low interest in both relevant and irrelevant nutrition information).
Respondents with a higher preference for smart phone apps as a source of nutrition information on chewing gum were more likely to have either a low or high interest in both relevant and irrelevant nutrition information (compared to the reference group: high interest in relevant and low interest in irrelevant nutrition information on chewing

Table 6

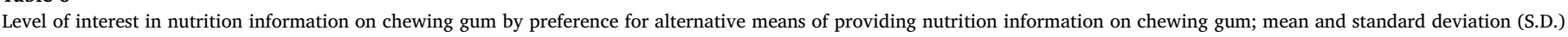

\begin{tabular}{|c|c|c|c|c|c|c|}
\hline \multirow{2}{*}{$\begin{array}{l}\text { Alternative nutrition information } \\
\text { sources }\end{array}$} & \multicolumn{4}{|c|}{ Level of interest in nutrition information on chewing gum } & \multirow[b]{2}{*}{ p-value ${ }^{\#}$} & \multirow[b]{2}{*}{$\begin{array}{l}\text { Effect size } \\
\eta^{2}\end{array}$} \\
\hline & $\begin{array}{l}\text { Low in relevant, low in } \\
\text { irrelevant } \\
(\mathrm{n}=1640)\end{array}$ & $\begin{array}{l}\text { Low in relevant, high in } \\
\text { irrelevant } \\
(\mathrm{n}=80)\end{array}$ & $\begin{array}{l}\text { High in relevant, low in } \\
\text { irrelevant } \\
(\mathrm{n}=587)\end{array}$ & $\begin{array}{l}\text { High in relevant, high in } \\
\text { irrelevant } \\
(\mathrm{n}=1193)\end{array}$ & & \\
\hline Advertising in magazines & $1.98(1.25)^{\mathrm{a}}$ & $2.25(1.28)^{\mathrm{b}}$ & $2.37(1.37)^{\mathrm{b}}$ & $2.97(1.25)^{\mathrm{c}}$ & $<0.001$ & 0.12 \\
\hline Advertising on TV & $2.18(1.40)^{\mathrm{a}}$ & $2.41(1.25)^{\mathrm{a}, \mathrm{b}}$ & $2.49(1.44)^{\mathrm{b}}$ & $3.08(1.31)^{\mathrm{c}}$ & $<0.001$ & 0.09 \\
\hline Product/brand website & $2.70(1.58)^{\mathrm{a}}$ & $2.81(1.52)^{\mathrm{a}}$ & $3.17(1.54)^{\mathrm{b}}$ & $3.48(1.28)^{\mathrm{c}}$ & $<0.001$ & 0.08 \\
\hline Health and nutrition websites & $2.49(1.52)^{\mathrm{a}}$ & $2.83(1.42)^{\mathrm{a}, \mathrm{b}}$ & $3.07(1.57)^{\mathrm{b}}$ & $3.42(1.29)^{\mathrm{c}}$ & $<0.001$ & 0.10 \\
\hline Product/brand social network sites & $1.89(1.27)^{\mathrm{a}}$ & $2.16(1.29)^{\mathrm{b}}$ & $2.16(1.35)^{\mathrm{b}}$ & $2.79(1.35)^{\mathrm{c}}$ & $<0.001$ & 0.10 \\
\hline Smart phone apps & $1.85(1.26)^{\mathrm{a}}$ & $1.97(1.32)^{\mathrm{a}, \mathrm{b}}$ & $2.06(1.35)^{\mathrm{b}}$ & $2.65(1.38)^{\mathrm{c}}$ & $<0.001$ & 0.08 \\
\hline Banners, posters, billboards outside & $1.80(1.16)^{\mathrm{a}}$ & $2.25(1.29)^{\mathrm{b}}$ & $2.12(1.26)^{\mathrm{b}}$ & $2.75(1.27)^{\mathrm{c}}$ & $<0.001$ & 0.12 \\
\hline $\begin{array}{l}\text { Direct mail/information through the } \\
\text { post }\end{array}$ & $1.70(1.13)^{\mathrm{a}}$ & $2.18(1.35)^{\mathrm{b}}$ & $1.97(1.25)^{\mathrm{b}}$ & $2.63(1.31)^{\mathrm{c}}$ & $<0.001$ & 0.11 \\
\hline In the shop aisle/on-shelf & $2.84(1.59)^{\mathrm{a}}$ & $3.00(1.51)^{\mathrm{a}}$ & $3.57(1.43)^{\mathrm{b}}$ & $3.59(1.23)^{\mathrm{b}}$ & $<0.001$ & 0.09 \\
\hline $\begin{array}{l}\text { Information in store (like on posters, } \\
\text { banners) }\end{array}$ & $2.30(1.43)^{\mathrm{a}}$ & $2.61(1.43)^{\mathrm{b}}$ & $2.74(1.42)^{\mathrm{b}}$ & $3.10(1.27)^{\mathrm{c}}$ & $<0.001$ & 0.09 \\
\hline
\end{tabular}

Notes: ${ }^{\#}$ p-values from one-way ANOVA F-tests; superscripts ${ }^{\text {a,b,c }}$ indicate significantly different means using the Tukey HSD post hoc comparison tests. 


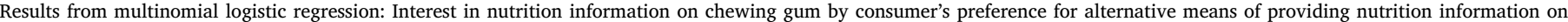
chewing gum and chewing gum behaviour; odds-ratio (95\% CI).

\begin{tabular}{|c|c|c|c|c|}
\hline & & \multicolumn{3}{|c|}{$\begin{array}{l}\text { Level of interest in nutrition information on chewing gum (relative to high in relevant, low in } \\
\text { irrelevant) }\end{array}$} \\
\hline & & $\begin{array}{l}\text { Low in relevant, low in } \\
\text { irrelevant }\end{array}$ & $\begin{array}{l}\text { Low in relevant, high in } \\
\text { irrelevant }\end{array}$ & $\begin{array}{l}\text { High in relevant, high in } \\
\text { irrelevant }\end{array}$ \\
\hline \multirow{10}{*}{$\begin{array}{l}\text { Interest in alternative nutrition } \\
\text { information sources }\end{array}$} & Advertising in magazines & $0.94(0.83-1.06)$ & $0.87(0.63-1.19)$ & $1.09(0.96-1.24)$ \\
\hline & Advertising on TV & $1.05(0.94-1.17)$ & $0.93(0.70-1.24)$ & $1.03(0.92-1.15)$ \\
\hline & Product/brand website & $1.01(0.92-1.11)$ & $0.86(0.67-1.09)$ & $0.98(0.89-1.08)$ \\
\hline & Health and nutrition websites & $0.86(0.78-0.94)^{k * k}$ & $1.04(0.83-1.32)$ & $1.00(0.91-1.11)$ \\
\hline & $\begin{array}{l}\text { Product/brand social network } \\
\text { sites }\end{array}$ & $0.98(0.88-1.09)$ & $1.04(0.79-1.35)$ & $1.10(0.99-1.22)$ \\
\hline & Smart phone apps & $1.11(1.01-1.23)^{*}$ & $0.93(0.72-1.21)$ & $1.18(1.07-1.30)^{* k t}$ \\
\hline & $\begin{array}{l}\text { Banners, posters, billboards } \\
\text { outside }\end{array}$ & $0.91(0.80-1.04)$ & $1.37(1.00-1.88)^{*}$ & $1.13(1.00-1.29)$ \\
\hline & $\begin{array}{l}\text { Direct mail/information through } \\
\text { the post }\end{array}$ & $1.03(0.91-1.16)$ & $1.27(0.96-1.69)$ & $1.21(1.08-1.35)^{* * *}$ \\
\hline & In the shop aisle/on-shelf & $0.77(0.71-0.84)^{* * * * x}$ & $0.75(0.60-0.93)^{\text {*** }}$ & $0.89(0.81-0.97)^{* * *}$ \\
\hline & $\begin{array}{l}\text { Information in store (like on } \\
\text { posters, banners) }\end{array}$ & $0.99(0.90-1.10)$ & $0.94(0.72-1.23)$ & $0.94(0.85-1.05)$ \\
\hline \multirow{5}{*}{$\begin{array}{l}\text { Chewing gum behaviour (vs. heavy } \\
\text { sugar-free user) }\end{array}$} & Medium sugar-free user & $0.75(0.57-0.97)^{*}$ & $1.42(0.69-2.92)$ & $1.35(1.02-1.79)^{*}$ \\
\hline & Low sugar-free user & $0.73(0.54-0.98)^{*}$ & $1.45(0.66-3.20)$ & $1.26(0.92-1.72)$ \\
\hline & Heavy regular user & $3.02(2.00-4.55)^{k+k * k}$ & $3.88(1.62-9.30)^{k * k}$ & $2.02(1.28-3.19)^{k * k}$ \\
\hline & Medium regular user & $2.22(1.44-3.43)^{k * k *}$ & $2.60(0.95-7.09)$ & $2.56(1.62-4.04)^{* k+k * k}$ \\
\hline & Low regular user & $2.10(1.16-3.80)^{*}$ & $0.71(0.09-5.82)$ & $1.70(0.90-3.21)$ \\
\hline Intercept & & $8.27(5.86-11.7)^{k * * *}$ & $0.19(0.08-0.44)^{k * * * *}$ & $0.55(0.37-0.82)^{* * *}$ \\
\hline
\end{tabular}

Notes: ${ }^{* * * *} \mathrm{p}<0.001 ;{ }^{* * *} \mathrm{p}<0.01 ;{ }^{*} \mathrm{p}<0.05$.

gum). Additionally, respondents with a higher preference for banners, posters and billboards outside were more likely to have a low interest in relevant and high interest in irrelevant nutrition information (compared to the reference group). Overall, respondents with a higher preference for nutrition information in the shop aisle/on-shelf were more likely to have a high interest in nutrition information relevant for chewing gum and a low interest in irrelevant information.

Concerning the type of chewing gum that is consumed, low and medium sugar-free gum users were more likely to have a high interest in nutrition information relevant for chewing gum and a low interest in irrelevant information as compared to heavy sugar-free gum users. Additionally, heavy users of regular compared to sugar-free chewing gum were less likely to have a high interest in nutrition information relevant for chewing gum and a low interest in irrelevant information. Furthermore, medium users of regular chewing gum were more likely to have either a low or high interest in both relevant and irrelevant nutrition information compared to heavy users of sugar-free chewing gum.

Users of regular chewing gum (regardless of their usage frequency) were more likely to have a low interest in both relevant and irrelevant nutrition information on chewing gum (compared to the referent group).

\section{Discussion}

The aim of this study was to explore European consumers' interest in nutrition information on (sugar-free) chewing gum and their preferred way of nutrition information provision. Seven countries have been selected for data collection, covering the geographical NorthSouth and East-West axes of Europe: United Kingdom, France, Germany, Italy, Sweden, Poland, and Estonia.

The results of this study showed that users of sugar-free chewing gum were more interested in general nutrition information and more interested in specific nutrition information relevant for chewing gum (i.e. energy (calories), carbohydrates, sugars, polyols) compared with regular chewing gum users. However, in spite of the high interest in general nutrition information, consumer interest in nutrition information placed on chewing gum package was found to be on a relatively low level. Perhaps chewing gum as a confectionary product is not perceived as a food product for which nutrition and health-related information matters, but rather as a hedonistic or refreshing food and therefore consumers do not seek for nutrition information on the package.

Consumers with a high interest in nutrition information relevant for chewing gum (i.e. energy, carbohydrates, sugars, and polyols) and a low interest in irrelevant nutrition information on chewing gum (i.e. fibre, fats, protein, and salt) are more likely to be female and older. This pattern of interest suggests a better awareness of which nutrients effectively may matter in chewing gum among females and older consumers. This finding corroborates with other studies on food and interest in nutrition information. Cavaliere, De Marchi, and Banterle (2016) as well as Cavaliere, Ricci, and Banterle (2015) indicated that female and older consumers were more interested in nutrition and health claims relative to men and the younger segments of the population. Grunert, Wills et al. (2010) found that gender had an indirect effect on the use of nutrition information and women were found to be more interested in healthy eating. In general, when purchasing food products, women have been shown to be more likely to consult nutrition labels than men (Hawkes, 2004). Men have been reported to be generally less interested in nutrition and health (Grunert, FernandezCelemin et al., 2010; Hoefkens et al., 2011). This has also been shown to translate into higher reported food label usage by females, compared to males (Blitstein \& Evans, 2006).

The top three nutrients that consumers are interested in for chewing gum were sugars, energy (calories) and carbohydrates. This corresponds with the previous results with regard to general nutrition information. The nutrients in food in general for which prime interest has been reported are fat, energy, salt and sugar, which are all so-called disqualifying nutrients (Grunert \& Wills, 2007), of which energy and sugar are clearly relevant in the case of chewing gum. Polyols were reported as one of the least interested nutrients. This is an interesting finding since polyols, i.e. sugar substitutes known also as "sugar alcohols", are the nonfermentable sugars which are beneficial in the prevention of dental caries (Deshpande \& Jadad, 2008). This might be a result of low awareness or knowledge about this ingredient. Consequently, this study exemplifies the need for effective communication 
about polyols and its link with the health benefit of eating chewing gum, not only to the heavy users of chewing gum, but also to the broader public.

Consumers with a high interest in nutrition information relevant for chewing gum and a low interest in irrelevant information had a higher general health interest and objective nutrition knowledge compared to the others. Consumers with a high interest in both relevant and irrelevant nutrition information on chewing gum perceive themselves as more knowledgeable about nutrition compared to the others. These findings correspond to previous studies that found that consumers' perceived nutrition knowledge positively influenced the use of nutrition labels (Drichoutis et al., 2006; Shine, O'Reilly, \& O'Sullivan, 1997). Nutrition knowledge may facilitate label use by increasing its perceived benefits and by increasing its efficiency (Drichoutis et al., 2006).

Information placed in the shop (on the shop aisle/on-shelf and on posters, banners) as well as information made available online (on a product/brand website or on a health and nutrition website) were found to be the most preferred alternative sources of nutrition information about chewing gum among all consumer groups. Consumer interest in new alternative sources of nutrition information provision such as smart phone apps and product/brand social network sites as well as more traditional information sources such as banners, posters, billboards outside and direct mail/information through the post was less pronounced across all groups. Consumers were moderately interested in advertising (on TV and in magazines) as alternative sources of providing nutrition information about chewing gum.

Furthermore, consumers with a stronger preference for health and nutrition websites as well as for nutrition information in the shop aisle/ on-shelf are more likely to have a high interest in nutrition information relevant for chewing gum and a low interest in irrelevant information. On the other hand, consumers with a stronger preference for smart phone apps are more likely to have a low or high interest in both relevant and irrelevant nutrition information.

Low and medium sugar-free gum users are more likely to have a high interest in nutrition information relevant for chewing gum and a low interest in irrelevant information as compared to heavy sugar-free gum users. This finding suggest that the low and medium user groups have a better awareness of what matters and what does not matter in terms of nutrients in chewing gum. Providing them with additional nutrition information that is relevant for chewing gum, e.g. dealing with energy, carbohydrates, sugars and polyols, entails opportunities for market penetration.

Heavy users of regular compared to sugar-free chewing gum are less likely to have a high interest in nutrition information relevant for chewing gum and a low interest in irrelevant information. Clearly, this group is less concerned about nutrition and health. Their main reason for consuming chewing gum might be habit and familiarity with the product, and/or they may know or like the taste of regular chewing gum. While the present study suggests that health-related or nutrition information is unlikely to change these consumers' habits - because of their disinterest in such information - further studies are warranted to reveal their true reason for sticking to regular chewing gum.

While extrapolation of the study findings beyond the study area is speculative, the study also faces limitations owing to the self-reported nature of the data collected and the possibility of social desirability in response behaviour. First, the self-reported nature of the data offers certain caveats due to a lack of insights into actual chewing gum consumption behaviour. However, the objective of this study has been to understand consumers' interest in nutrition information for chewing gum and where they would like to find and access such information. More behavioural research would complement the present study, for example through experimental settings testing the actual use of such nutrition information (e.g., through various channels) and its effects on choice, purchase and consumption frequency, hereby adding to the broader literature on nutrition labelling. Second, there is of course the possibility of a social desirability bias inherent in most online surveys.
Given the nature of this topic, however, no major areas of sensitivity or societal taboos could be identified and as such it is not expected that the answering behaviour or the results were strongly impacted in this way.

\section{Policy implications and conclusion}

While chewing gum has been exempt from nutrition labelling mandatory under the Food Information to Consumers (FIC) Regulation EU 1169/2011, there are on-going discussions regarding the revision of such exceptions. Such an eventual revision is particularly relevant for the subcategory of sugar-free chewing gum which, because 'sugar-free' is an official nutrition claim, would be required to provide nutrition information. In light of the limited pack size, alternative sources of nutrition information provision have been of interest as a way of offering the nutrient declaration to consumers without having to reduce its font size to an illegible status in order to squeeze it all on-pack. The present study has been a first step towards this direction and offers insights into consumer interest, attitudes and preferences for various alternative sources of information provision, specifically in relation to the nutrition information for chewing gum. Specifically, results of the present study indicate that consumers prefer information placed in the shop aisle/on shelf as well as information made available online (on a product/brand website or on a health and nutrition website) over other sources of nutrition information, such as smartphone apps or advertisements. Retailers could be encouraged to offer such information as a measure to aid product choice and offer transparency to consumers. Alternatively, devices in-store could be connected online and offer shoppers the possibility to visit selected (product or brand) websites to retrieve this information.

The findings of the present study are also linked to a more general debate concerning alternative sources of nutrition information provision. A small but growing body of literature investigates consumer preferences, familiarity with and likelihood of use of provided information other than on-pack. While one aspect may be the lack of space on-pack, information overload could serve as a stronger driver for finding new ways to offer relevant information to consumers, without overstraining them. A multitude of product-related information (marketing-related information like brand names, value-chain or process quality related information like organic or fair trade, as well as package design on the one hand, and various health- and nutrition-related claims on the other) is presented to consumers - for a multitude of products at the point-of-sales. Rational decisions based on all available information are close to impossible to make and choices are often reduced down to simple heuristics. The grand question that public health policy is faced with - how to improve public health and motivate healthier choices and lifestyles - can only be tackled once novel ways of informing consumers are developed. The use of alternative ways of providing such information could be one way of approaching this task.

Lastly, and more specifically based on the results of the present study, heavy users (of regular chewing gum) displaying less interest in relevant nutrition information on chewing gum pose a consumer profile that may benefit from increased communication activities. Such measures would require further research into the drivers for regular chewing gum choice and consumption, other than nutrition and health benefits. Based on such findings, policy-led campaigns could be designed to target frequent chewing gum users and highlight the nutritional value of sugar-free vs. regular chewing gum as well as potential health benefits. Further research could look at the attitudinal characteristics and motives of such segments in order to better understand the reason for choice (i.e. of regular chewing gum) as well as draw parallels to other types of food and drinks where similar patterns may be observed. Reasons for choice that differ from health-related drivers may help explain the choice of less healthful alternatives or the lack of interest in nutrition information on food labels. A better understanding of this interplay would be of great value to the overall field of nutrition labelling in relation to public health policy and food consumer 


\section{preferences.}

Chewing gum is a confectionary product with some potential health benefits and small pack size limiting the space available to provide the information. This study exemplifies the need for effective communication about polyols and its link with the health benefit of eating chewing gum to the broader public. Alternative sources of nutrition information about chewing gum, particularly information placed in the shop as well as information made available online (on a product/brand website or on a health and nutrition website) emerge as potentially promising ways to communicate with chewing gum users.

\section{Acknowledgement}

EUFIC receives part of its funding from the food and drink industry and provided funds to Ghent University for contributing to this study.

\section{References}

Blitstein, J. L., \& Evans, W. D. (2006). Use of nutrition facts panels among adults who make household food purchasing decisions. Journal of Nutrition Education and Behavior, 38, 360-364.

Brislin, R. W. (1970). Back-translation for cross-cultural research. Journal of Cross-Cultural Psychology, 1, 185-216.

Campos, S., Doxey, J., \& Hammond, D. (2011). Nutrition labels on pre-packaged foods: A systematic review. Public Health Nutrition, 14, 1496-1506.

Cavaliere, A., De Marchi, E., \& Banterle, A. (2016). Does consumer health-orientation affect the use of nutrition facts panel and claims? An empirical analysis in Italy. Food Quality and Preference, 54, 110-116.

Cavaliere, A., Ricci, E. C., \& Banterle, A. (2015). Nutrition and health claims: Who is interested? An empirical analysis of consumer preferences in Italy. Food Quality and Preference, 41, 44-51.

Deshpande, A., \& Jadad, A. R. (2008). The impact of polyol-containing chewing gums on dental caries: A systematic review of original randomized controlled trials and observational studies. Journal of the American Dental Association, 139, 1602-1614.

Dickson-Spillmann, M., Siegrist, M., \& Keller, C. (2011). Development and validation of a short, consumer-oriented nutrition knowledge questionnaire. Appetite, 56, 617-620.

Dimitriou, M., Giazitzi, K., Stavridi, E., Palisidis, G., Karathanos, V., \& Boskou, G. (2017). Evaluation of an electronic application for nutritional information in food service outlets: A pilot mhealth application. International Journal of Reliable and Quality EHealthcare, 6, 46-58.

Drichoutis, A. C., Lazaridis, P., \& Nayga, R. M. (2006). Consumers' use of nutritional labels: A review of research studies and issues. Academy of Marketing Science Review, $10,1-12$.

EC Directorate General for Health and Consumer Protection (2005). The European consumers' attitudes regarding product labelling-qualitative study in 28 European countries. Versailles: European Commission.

Epstein, L. H., Finkelstein, E. A., Katz, D. L., Jankowiak, N., Pudlewski, C., \& Paluch, R. A. (2016). Effects of nutrient profiling and price changes based on $\mathrm{NuVal}^{\varpi}$ scores on food purchasing in an online experimental supermarket. Public Health Nutrition, 19, 2157-2164.

European Heart Network (2007). Review of front of pack nutrition schemes. Brussels: European Heart Foundation.

Freedman, M. R., \& Connors, R. (2010). Point-of-purchase nutrition information influences food-purchasing behaviors of college students: A pilot study. Journal of the American Dietetic Association, 110, 1222-1226.

Galmarini, M. V., Symoneaux, R., Visalli, M., Zamora, M. C., \& Schlich, P. (2015). Static vs. dynamic liking in chewing gum: A new approach using a background task and a natural setting. Food Quality and Preference, 40, 381-386.

Galmarini, M. V., Symoneaux, R., Visalli, M., Zamora, M. C., \& Schlich, P. (2016). Could Time-Intensity by a trained panel be replaced with a progressive profile done by consumers? A case on chewing-gum. Food Quality and Preference, 48, 274-282.

Gregori, D., Ballali, S., Vögele, C., Gafare, C. E., Stefanini, G., \& Widhalm, K. (2014). Evaluating food front-of-pack labelling: A pan-European survey on consumers' attitudes toward food labelling. International Journal of Food Sciences and Nutrition, 65, 177-186.

Grunert, K. G., Fernandez-Celemin, L., Wills, J. M., Storcksdieck genannt Bonsmann, S., \& Nureeva, L. (2010a). Use and understanding of nutrition information on food labels in six European countries, Journal of Public Health, 18, 261-277.

Grunert, K., \& Wills, J. M. (2007). A review of European research on consumer response to nutrition information on food labels. Journal of Public Health, 15, 385-399.

Grunert, K. G., Wills, J. M., \& Fernandez-Celemin, L. (2010b). Nutrition knowledge, and use and understanding of nutrition information on food labels among consumers in the UK. Appetite, 55, 177-189.

Grunert, K. G., Wills, J. M., Fernandez-Celemin, L., Lähteenmäki, L., Scholderer, J., \& Storcksdieck genannt Bonsmann, S. (2012). Socio-demographic and attitudinal determinants of nutrition knowledge of food shoppers in six European countries. Food Quality and Preference, 26, 166-177.

Harlow, L. L. (2005). The essence of multivariate thinking: Basic themes and methods. Mahwah, New Jersey: Lawrence Erlbaum Associates Publishers.

Hawkes, C. (2004). Nutrition labels and health claims: The global regulatory environment. Geneva: World Health Organisation.

Hearty, A., Lau, A., \& Roberts, A. (2014). Chewing gum intake in Europe: A survey of intakes in France, Germany, Italy, Spain and the UK. Food Additives \& Contaminants: Part A, 31, 1147-1157.

Hersey, J. C., Wohlgenant, K. C., Arsenault, J. E., Kosa, K. M., \& Muth, M. K. (2013). Effects of front-of-package and shelf nutrition labeling systems on consumers. Nutrition Reviews, 71, 1-14.

Hetherington, M., \& Boyland, E. (2007). Short-term effects of chewing gum on snack intake and appetite. Appetite, 48, 307-401.

Hetherington, M., \& Regan, M. (2011). Effects of chewing gum on short-term appetite regulation in moderately restrained eaters. Appetite, 57, 475-482.

Hieke, S., \& Wills, J. M. (2012). Nutrition labelling - Is it effective in encouraging healthy eating? $C A B$ Reviews, $7,1-7$.

Hoefkens, C., Verbeke, W., \& Van Camp, J. (2011). European consumers' perceived importance of qualifying and disqualifying nutrients in food choices. Food Quality and Preference, 22, 550-558.

Hung, Y., Grunert, K. G., Hoefkens, C., Hieke, S., \& Verbeke, W. (2017). Motivation outweighs ability in explaining European consumers' use of health claims. Food Quality and Preference, 58, 34-44.

Maneesriwongul, W., \& Dixon, J. K. (2004). Instrument translation process: A methods review. Journal of Advanced Nursing, 48, 175-186.

McFadden, D. (1974). Conditional logit analysis of qualitative choice behaviour. In P. Zarembka (Ed.). Frontiers in econometrics (pp. 104-142). New York: Academic Press.

Onyper, S. V., Carr, T. L., Farrar, J. S., \& Floyd, B. R. (2011). Cognitive advantages of chewing gum. Now you see them, now you don't. Appetite, 57, 321-328.

Pieniak, Z., Aertsens, J., \& Verbeke, W. (2010). Subjective and objective knowledge as determinants of organic vegetables consumption. Food Quality and Preference, 21, 581-588.

Rebollar, R., Lidón, I., Serrano, A., Martín, J., \& Fernández, M. J. (2012). Influence of chewing gum packaging design on consumer expectation and willingness to buy. An analysis of functional, sensory and experience attributes. Food Quality and Preference, $24,162-170$.

Ribelles Llop, M., Guinot Jimeno, F., Mayné Acién, R., \& Bellet Dalmau, L. (2010). Effects of xylitol chewing gum on salivary flow rate, $\mathrm{pH}$, buffering capacity and presence of Streptococcus mutans in saliva. European Journal of Paediatric Dentistry, 11, 9-14.

Roininen, K., Lähteenmäki, L., \& Tuorila, H. (1999). Quantification of consumer attitudes to health and hedonic characteristics of foods. Appetite, 33, 71-88.

Seymour, J. D., Yaroch, A. L., Serdula, M., Blanck, H. M., \& Khan, L. K. (2004). Impact of nutrition environmental interventions on point-of-purchase behavior in adults: A review. Preventive Medicine, 39, S108-S136.

Shine, A., O'Reilly, S., \& O'Sullivan, K. (1997). Consumer use of nutrition labelling. British Food Journal, 99, 290-296.

Smith, A., Chaplin, K., \& Wadsworth, E. (2012). Chewing gum, occupational stress, work performance and wellbeing. An intervention study. Appetite, 58, 1083-1086.

Stones C. (2106). Online food nutrition labelling in the UK: how consistent are supermarkets in their presentation of nutrition labels online? Public Health Nutrition, 19, $2175-2184$.

Storcksdieck genannt Bonsmann, S., Fernandez Celemin, L., Larranaga, A., Egger, S., Wills, J. M., Hodgkins, C., et al. (2010). Penetration of nutrition information on food labels across the EU-27 plus Turkey. European Journal of Clinical Nutrition, 64, 1379-1385.

Urala, N., \& Lähteenmäki, L. (2004). Attitudes behind consumers' willingness to use functional food. Food Quality and Preference, 15, 793-805.

Urala, N., \& Lätheenmäki, L. (2007). Consumers' changing attitudes towards functional foods. Food Quality and Preference, 18, 1-12.

Williams, P., Ridges, L., Batterham, M., Ripper, B., \& Hung, M. C. (2008). Australian consumer attitudes to health claim - Food product compatibility for functional foods. Food Policy, 33, 640-643. 